\title{
Review of Latest Developments in PEM Fuel Cell Research with Application to Hydrogen Powered Drones
}

\author{
B. Day ${ }^{1}$ and A. Pourmovahed ${ }^{2}$ \\ ${ }^{1}$ Mechanical Engineering Student \\ Phone: +001 740507 9641, e-mail: $\underline{\text { day9348@ kettering.edu }}$ \\ ${ }^{2}$ Professor of Mechanical Engineering \\ Phone: +001 810762 9758, e-mail: apourmov@ kettering.edu
}

Kettering University

Flint, Michigan, U.S.A. 48504

\begin{abstract}
Fuel cells are becoming an increasingly more enticing option to power drones for extended use applications. This is because under certain conditions, fuel cell systems are able to more efficiently store fuel and, therefore, energy compared to standard battery options. This reality has been proven through multiple research efforts and is reviewed in this paper. It is necessary to review the current state of PEM fuel cell technology for drone applications to determine the extent of its limitations and feasibility. For this reason, the latest developments in low temperature and high temperature PEM fuel cells were studied including their limitations and sensitivity to contamination with a focus on drone applications. It has been reported that hydrogen powered fuel cell systems are more efficient than conventional battery applications when the energy content is higher than $4 \mathrm{MJ}$. A hybrid fuel cell and battery powertrain is preferred for the purpose of counterbalancing the deficiencies of both individual cases. Currently available products were explored, and it was found that there are fuel cell systems available that are capable of powering drones in excess of $23 \mathrm{~kg}(50 \mathrm{lb})$.
\end{abstract}

Key words. Fuel Cells, Proton Exchange Membrane (PEM), Drone, High Temperature Proton Exchange Membrane (HT-PEM), Polybenzimidazole (PBI)

\section{Introduction}

Drones are limited by multiple factors, but two major limiting factors are weight and operation time. These are areas where fuel cell systems can be superior when compared to batteries under certain conditions. To investigate potential benefits that fuel cells can provide compared to batteries, it is necessary to study the current state of fuel cell technology, current research and future possibilities to better understand their limitations and applications.

The specific type of fuel cell investigated in this article is the PEM fuel cell. Fuel cells operate by converting chemical potential energy into electrical energy. A Proton Exchange Membrane (PEM) fuel cell uses hydrogen gas as fuel and oxygen. It produces electricity, water and heat as illustrated in Fig. 1.

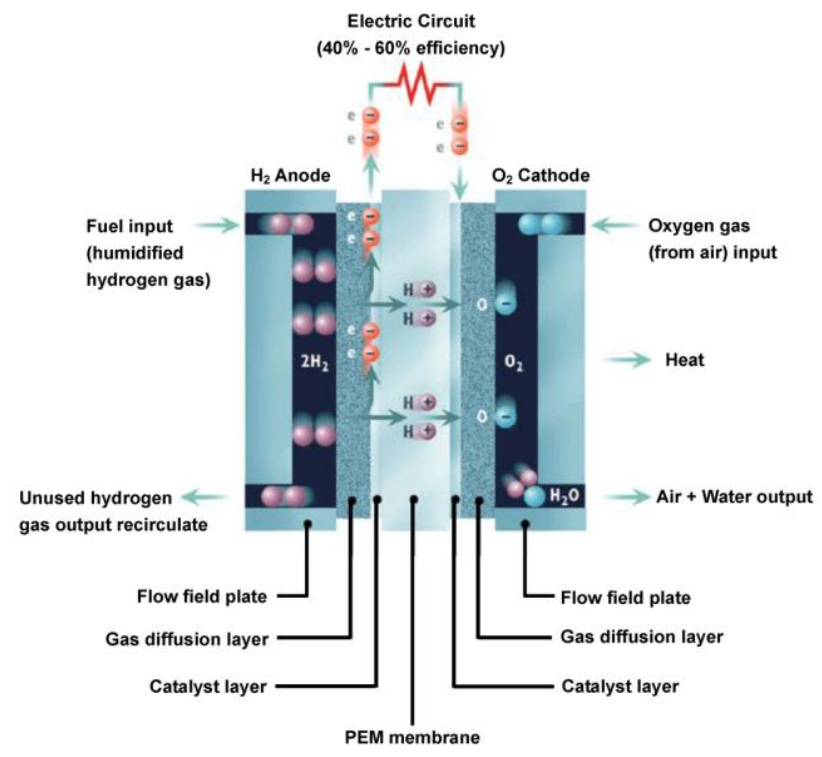

Fig. 1. Operation of a PEM fuel cell [1]

A PEM Fuel Cell has four main components: the anode, the cathode, the electrolyte and the catalyst. The anode is the negative post of the fuel cell; it conducts the electrons from the hydrogen molecules to the external circuit and channels and disperses the hydrogen along the catalyst. The cathode is the positive post of the fuel cell; it conducts the electrons from the external circuit to the catalyst and distributes the oxygen along the catalyst. The electrolyte in this case is the Proton Exchange Membrane (PEM). The membrane blocks electrons while conducting positively charged ions (protons). In a PEM fuel cell, the membrane needs to be hydrated to operate. The last main component, the catalyst, facilitates the reaction of the oxygen and hydrogen. A majority of technological improvements for PEM fuel cells come from changes or advances in one of these four main components. In this study, we reviewed the latest developments in low and high temperature PEM fuel cell research and technology, their limitations and sensitivity to 
contamination with application to hydrogen powered drones. We also reviewed fuel cell systems that are available and capable of powering a $23 \mathrm{~kg}(50 \mathrm{lb})$ drone. A fuel cell powered drone is shown in Fig. 2.

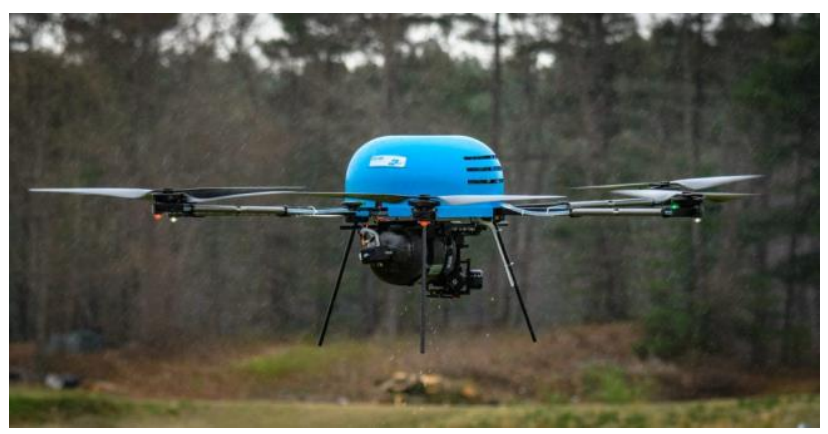

Fig. 2. A fuel-cell powered drone [2]

\section{Low Temperature PEM Fuel Cell Research}

Ballard Power Systems develop and produce PEM Fuel Cells for various applications. They claim that fuel cell catalysts are the key to "the future of fuel cell technology" and improvements in catalyst technology will lower fuel cell cost, improve durability and increase the range of fuel cell operating conditions [3]. Most PEM fuel cells utilize platinum as the primary element for their catalysts. The platinum usually contributes $10-15 \%$ of the cost of a fuel cell stack. Hence it is possible to significantly reduce PEM fuel cell cost by reducing the amount of platinum used. This is where innovations in catalyst development can make a significant impact. Ballard recently announced the world's first non-precious metal catalyst PEM fuel cell. Their new design contains $80 \%$ less platinum and is also more tolerant to air contaminants [3].

Currently, the most common PEM used for fuel cells is Nafion which contains a copolymer of tetrafluoroethylene (TFE) foundation and sulfonic acid-terminated perfluoro vinyl ether pendant. Nafion has high proton conductivity at $\left(0.13 \mathrm{~S} / \mathrm{cm}\right.$ at $75^{\circ} \mathrm{C}$ and $\left.100 \% \mathrm{RH}\right)$ and has an operation time of over 60,000 hours. It is also chemically stable. All these factors make Nafion quite attractive for use in fuel cells. The downside to Nafion is that it is expensive to make and requires hydration in order to conduct protons and avoid breaking down [4]. Several studies have been conducted with the aim of incorporating hygroscopic inorganic materials like $\mathrm{ZrO}_{2}, \mathrm{TiO}_{2}, \mathrm{TiSiO}_{4}$ and Silica as filters in the polymer matrix. These materials have shown promising results enabling higher water retention which allows proton conductivity over a larger range of temperatures. There have also been experiments using new catalyst materials such as ruthenium or palladium instead of $\mathrm{Pt}$ or replacing the catalysts with non-precious metal catalysts. There are indications that Fe, Co or Mn could be used, but their instability under acidic conditions still prevents them from being used in practical applications [4].

\section{High Temperature PEM Fuel Cell Research}

Recently, there have been several developments in HTPEM fuel cell technology. One recent study investigated the development of acid-based polymer membranes, inorganic proton conductors and organic-inorganic composite materials [5]. While hydrogen has a high volumetric energy density $(1.9 \mathrm{MJ} / \mathrm{L}$ at $20 \mathrm{MPa})$ liquid alcohol fuels such as methanol have a higher value (17.28 MJ/L) which makes them an enticing fuel source except that they have low catalyst activity at low temperatures. PEM fuel cell catalysts generally have a very low tolerance for $\mathrm{CO}$, less than 10-20 ppm. If the $\mathrm{CO}$ is not properly reformed it will poison the catalyst. Therefore acid-doped polybenzimidazole (PBI) membranes are developed for HT-PEM fuel cells [5]. These (PBI) membranes have been shown to have a tolerance as high as $30,000 \mathrm{ppm}$ at temperatures between $150-200{ }^{\circ} \mathrm{C}$. These HT-PEM fuel cells are equipped with external methanol reformers. This allows the fuel cell reaction to be exothermic; and the heat is used for preheating. This increases the overall performance of the fuel cell stack [5]. It has been shown that with HT-PEM fuel cells, increasing the operational temperature will usually decrease the durability of the cell. It was found that due to the dehydration and evaporation of phosphoric acid (PA) and degradation of the polymer at high temperature conditions, the PA loss rate is increased by one order of magnitude from $150{ }^{\circ} \mathrm{C}$ to $190{ }^{\circ} \mathrm{C}$. This corresponds to about $8000 \mathrm{~h}$ of lost operation time [5]. It has been found that the incorporation of inorganic fillers in composite membranes can help stabilize the PA-doped polymer membranes at high temperatures. In one case, PA-doped phosphotungstic acid (PWA) mesoporous silica composite membranes were used and provided membrane cell stability for almost 3000 $\mathrm{h}$ at $200{ }^{\circ} \mathrm{C}$. This is comparable to a PA/PBI fuel cell operating at $170{ }^{\circ} \mathrm{C}$. The difference between PA/PBI and the PA/PBI/PWA-meso-silica can be seen in Fig. 3.
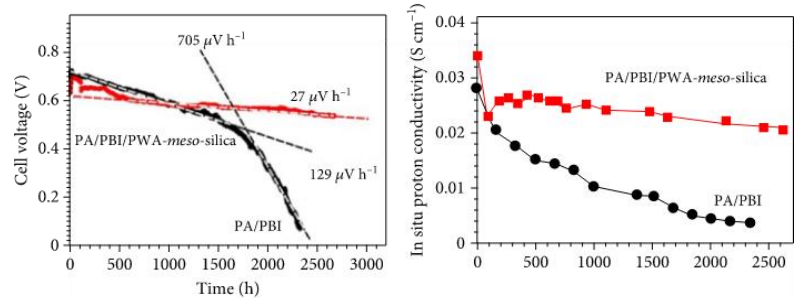

(a)
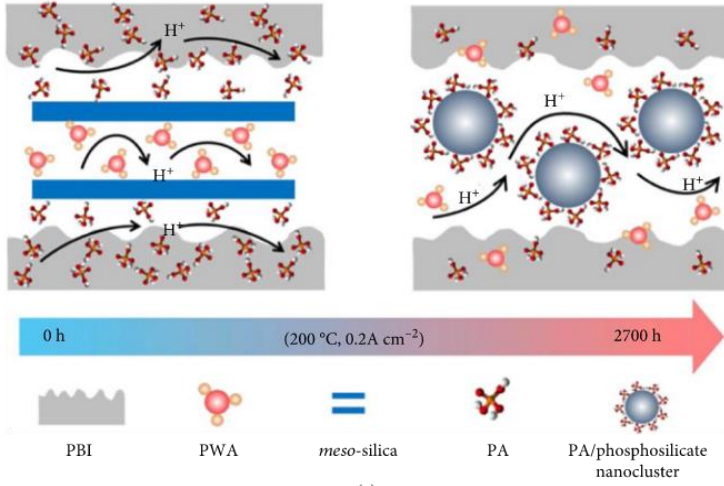
nanocluster

Fig. 3. Measured performance of PA/PBI and PA/PBI/PWA-meso-silica [5] 
PBI HT-PEM fuel cells have become popular due to their high thermal and chemical stability, but they tend to be expensive to produce. This makes it necessary to investigate alternative polymer materials [5]. If we can develop more efficient and stable HT-PEM fuel cells, it will be possible to use liquid fuels like methanol.

\section{Drone Related PEM Fuel Cell Research}

It has been found that hydrogen PEM fuel cells can increase the range of a drone between 2 to 6 times that of a drone using the same weight of Lithium Polymer (LiPo) batteries. This of course does depend somewhat on the drone platform but overall, this is a significant increase in flight time [6]. PEM fuel cells are ideal for drone usage due to their small size and light weight. According to [7], fuel cell powertrains provide higher endurance compared to battery configurations at energy contents higher than 4 MJ. Fuel cell powertrains perform better when the amount of energy stored is increased. This is due to the negligible increase in aircraft empty mass which means very little redesigning if any is needed for fuel cell powered drones compared to battery powered drones where an increase in energy content does lead to a significant increase in aircraft empty mass [7]. It has been shown that PEM fuel cell systems for drones operate much more efficiently in a hybrid system that also utilizes a battery. This is because the battery can provide the peak power needed for take-off and when the fuel cell requires purging. With the fuel cell alone, it is possible that it may not be able to supply the necessary energy to get or keep the drone in the air [8]. A parallel layout for such a hybrid system is shown in Fig. 4.

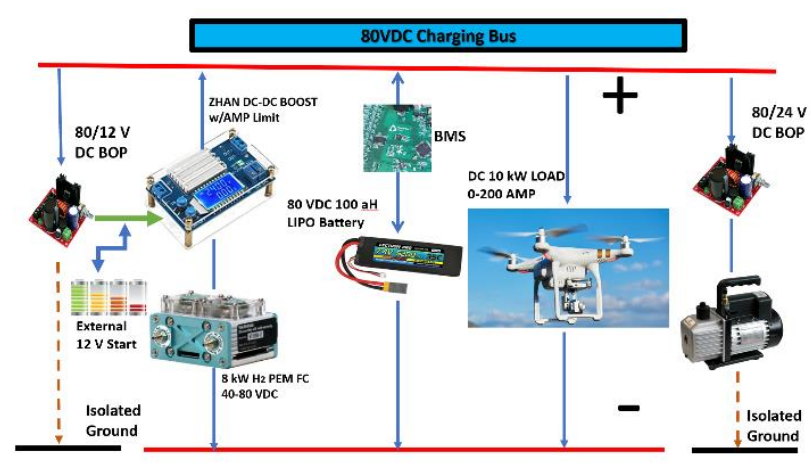

Fig. 4. Layout for a PEMFC battery hybrid powertrain for a drone

BOP: Balance of Plant BMS: Battery Management System Courtesy of Dr. K. J. Berry, Kettering University Center for Fuel Cell Systems and Powertrain Integration

With a hybrid PEMFC and battery powertrain, during takeoff and ascension both the battery and the fuel cell stack are used to provide the total power needed for the drone. Accumulation of water vapor in the fuel cell stack is limited since the stack is assisted by the battery. Once the battery is turned off and the fuel cell stack is supplying the full power, accumulation of water vapor causes inconsistency in the voltage supplied. This is when the vapor needs to be purged. When the purge occurs, the fuel cell voltage drops, and the battery takes over to compensate until the fuel cell resumes it optimum performance [9].
Efficient fuel cell hybrid systems are described as "parallel" FC hybrid power systems where the fuel cell and the battery work together all the time to meet the load demand and to charge the battery as needed. Normally, in a hybrid fuel cell system, the energy storage module is designed to provide the "peak" current/energy demand A/Ah and the fuel cell provides the average or nominal current/power demand $\mathrm{A} / \mathrm{kWh}$ while also ensuring the battery energy storage is maintained at a minimum level. The battery handles most of the abusive transient spikes, and the fuel cell handles the steady state demand.

\section{Limitations of PEM Fuel Cells}

One major limitation of PEM fuel cells is related to the geometry of the gas diffuser and supply channels. One source found that using two or three serpentine channels yield the best results. This is due to the lower number of channels conducting higher pressures which helps prevent water flooding in the diffuser [10]. Other limitations of PEM fuel cells come from the materials used as discussed earlier. Most PEM fuel cells use Nafion which requires hydration to operate. This imposes restrictions on the fuel cell such as its operation temperature [4]. There are also the limitations of the catalyst as discussed earlier [3,4]. One inherent limitation of fuel cells is that they require constant fuel supply. If they are not supplied with reactant quickly enough to meet current demands, they will starve.

\section{PEM Fuel Cell Sensitivity to Contamination}

One study found that even trace amounts of contamination in either the fuel or air supply or even the fuel cell system components can poison the anode, membrane and cathode. Fuel cell components are especially susceptible to contaminants at low temperatures. These contaminants can severely affect the fuel cell's performance [11]. Fuel cell contamination generally affects three main characteristics of a fuel cell: the electrode kinetics, conductivity and mass transfer. Currently, the most effective way to reduce fuel cell contamination is through the fuel. The most popular treatments to mitigate anode contamination are pretreatment of reformate, oxidant-bleeding, $\mathrm{CO}$ tolerant catalyst synthesis and high temperature operation. Although these treatments do help maintain a pure fuel source, there are problems with all these solutions: pretreatment and catalyst synthesis are both expensive, oxidant-bleeding is hard to control and the PEM's tolerance to heat sets limits for operation temperature. As a result, it is necessary to look for new methods [11].

The presence of $\mathrm{CO}_{2}$ in fuel has been proven to negatively affect PEM fuel cell performance. For low temperature PEM fuel cells, it is believed that $\mathrm{CO}_{2}$ contamination increases with operating temperature due to the reverse water gas shift reaction (RWGS). For HT-PEM fuel cells, $\mathrm{CO}_{2}$ contamination seems to be largely influenced by current density. It has also been observed that low temperature PEM fuel cells exhibit a higher tolerance to $\mathrm{CO}_{2}$ contamination when they are better hydrated [12]. The effect of $\mathrm{CO}_{2}$ contamination on a low temperature PEM fuel cell is shown in Fig. 5. 


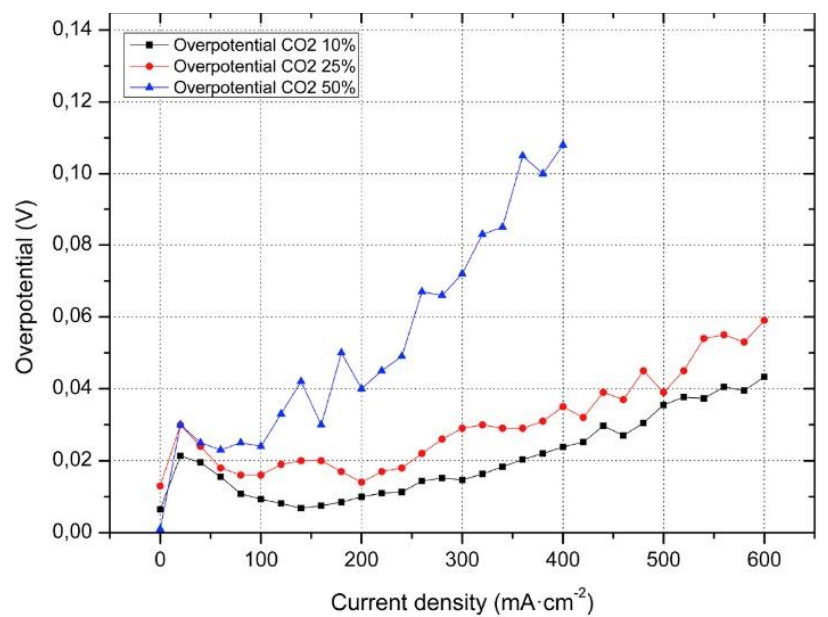

Fig. 5. Effect of $\mathrm{CO}_{2}$ contamination on a low temperature PEM fuel cell operating at $60^{\circ} \mathrm{C}$ [12]

Similar results for a HT-PEM fuel cell can be seen in Figs. 6 and 7.

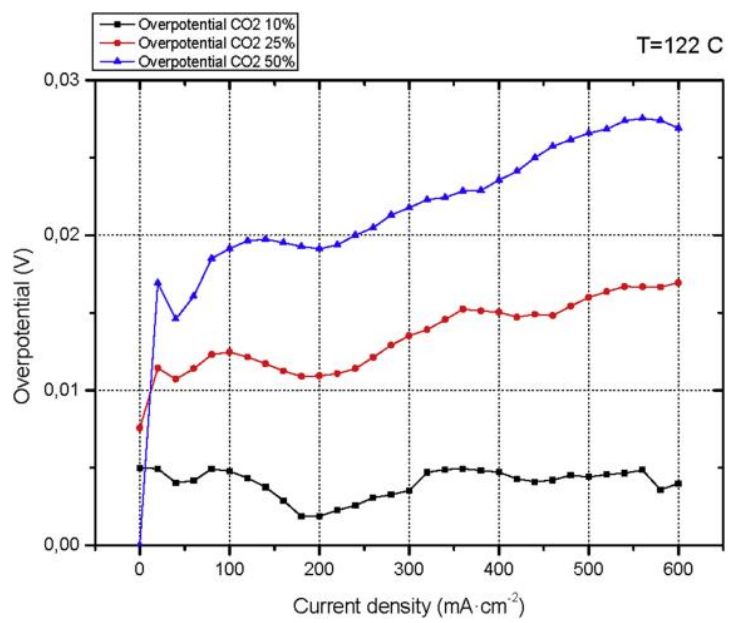

Fig. 6. Effect of $\mathrm{CO}_{2}$ contamination on an HT-PEM fuel cell operation at $122{ }^{\circ} \mathrm{C}[12]$

For the HT-PEM fuel cell, the cell should have better performance at $160{ }^{\circ} \mathrm{C}$ compared to $122{ }^{\circ} \mathrm{C}$ but due to the endothermic nature of the RWGS reaction, the higher operating temperature produces more $\mathrm{CO}$ which in turn creates greater voltage loss at the higher temperature [12].

\section{Fuel Cell System Selection for a 50 lb Drone}

If we look at the currently available hydrogen powered PEM fuel cell systems on the market, there are a wide variety of options to choose from. We were looking specifically for a PEM fuel cell system capable of powering a $23 \mathrm{~kg}(50 \mathrm{lb})$ drone. It depends on the type of drone but for a rough estimate, the fuel cell should be able to provide a minimum of $1.6 \mathrm{~kW}$ of continuous power [8]. The Fuel Cell Module also needs to be able to run in a hybrid configuration using batteries preferably LiPo. As we learned earlier, fuel cells are more efficient than batteries when they carry an energy content of $4 \mathrm{MJ}$ or greater [7].

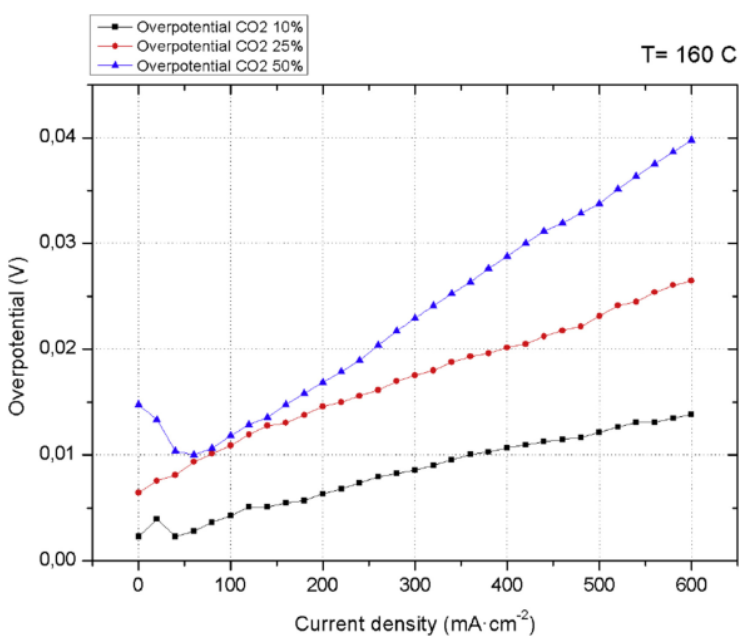

Fig. 7. Effect of $\mathrm{CO}_{2}$ contamination on a HT-PEM fuel cell operation at $160^{\circ} \mathrm{C}[12]$

Hence, a minimum of $4 \mathrm{MJ}$ of energy content will be required; any additional energy will provide additional flight time.

Intelligent Energy is a company that provides multiple options for PEM fuel cells for UAV and drone applications. They have a $2.4 \mathrm{~kW}$ continuous power Fuel Cell Module which should be more than enough to power a $50 \mathrm{lb}$ drone. This $2.4 \mathrm{~kW}$ Module is hybrid compatible and uses $26 \mathrm{~S}$ Lipo Batteries in series [13]. If we look for a compatible storage tank the company Luxfer has a 1586 W.h tank (the L64G) which is equivalent to 5.7 MJ. This meets our $4 \mathrm{MJ}$ minimum requirement [14].

\section{Conclusions}

With current technology, PEM fuel cells provide a reasonable alternative to batteries for powering drones. In some cases, fuel cells are more efficient and provide a much greater flight time when compared to batteries. Although there are several problems with the current fuel cell technology, recent advances in both low temperature and high temperature fuel cells make them more appealing for an increasing variety of applications. Currently, the biggest potential advances in PEM Fuel Cell technology still lay in the catalyst technology and finding alternatives to platinum $(\mathrm{Pt})$ and in finding new durable materials for the membrane that are less sensitive to contamination and less dependent on hydration.

\section{References}

[1] FuelCellStore, Retrieved 24 Dec. 2020, from Fuel Cell Characterization (fuelcellstore.com)

[2] Ball, M., Fuel Cell Solutions for Commercial UAVs Unveiled, 29 Apr. 2019,

Fuel Cell Solutions for Commercial UAVs Unveiled | Unmanned Systems Technology

[3] Colbow, K., What Are the Latest Developments in Fuel Cell Catalyst Technology? Retrieved 27 Sep. 2020, from https://blog.ballard.com/latest-developments-in-fuel-celltechnology 
[4] Wang, Y., Ruiz Diaz, D., Chen, K., Wang, Z., \& Adroher, X. (2020). Materials, technological status, and fundamentals of PEM fuel cells - A review. Materials Today, 32, 178-203. doi: 10.1016/j.mattod.2019.06.005

[5] Zhang, J., Aili, D., Lu, S., Li, Q., \& Jiang, S. (8 Jun 2020), Advancement Toward Polymer Electrolyte Membrane Fuel Cells at Elevated Temperatures. Retrieved 27 Sep. 2020, from https://spj.sciencemag.org/journals/research/2020/9089405/

[6] PEM Fuel Cells for Drones, UAVs, and Robotics. (n.d.). Retrieved 27 Sep. 2020, from https://www.fuelcellstore.com/fuelcell-stacks/uav-fuel-cell-stacks

[7] Donateo, T., Ficarella, A., Spedicato, L., Arista, A., \& Ferraro, M. (2017). A new approach to calculating endurance in electric flight and comparing fuel cells and batteries. Applied Energy, 187, 807-819. doi: 10.1016/j.apenergy.2016.11.100

[8] Ustolin, F., \& Taccani, R. (2018). Fuel cells for airborne usage: Energy storage comparison. International Journal of Hydrogen Energy, 43(26), 11853-11861. doi: 10.1016/j.ijhydene.2018.04.017

[9] Renau, J., Sánchez, F., Lozano, A., Barroso, J., \& Barreras, F. (2017), Analysis of the performance of a passive hybrid powerplant to power a lightweight unmanned aerial vehicle for a high altitude mission, Journal Of Power Sources, 356, 124-132. doi: 10.1016/j.jpowsour.2017.04.090
[10] Zhukovsky, K., \& Pozio, A. (2004), Maximum current limitations of the PEM fuel cell with serpentine gas supply channels. Journal of Power Sources, 130(1-2), 95-105.

[11] A review of PEM hydrogen fuel cell contamination: Impacts, mechanisms, and mitigation. (2020), Retrieved 30 Sep 2020 from https://www.researchgate.net/publication/44058123_A_review_ of_PEM_hydrogen_fuel_cell_contamination_Impacts_mechanis ms_and_mitigation

[12] Díaz, M., Iranzo, A., Rosa, F., Isorna, F., López, E., \& Bolivar, J. (2015), Effect of carbon dioxide on the contamination of low temperature and high temperature PEM (polymer electrolyte membrane) fuel cells. Influence of temperature, relative humidity and analysis of regeneration processes. Energy, 90, 299-309. doi: 10.1016/j.energy.2015.06.097

[13] 2.4 kW Fuel Cell Power Module Lightweight power module for UAVs and other portable applications, Retrieved $30 \mathrm{Sep}$ 2020, from https://www.intelligentenergy.com/uploads/product_docs $/ 2.4 \mathrm{~kW}$ datasheet.pdf

[14] Cylinder options for UAVs, Retrieved 30 Sep. 2020, from https://www.intelligentenergy.com/uploads/product_docs/61126_IE__Cylinder_Guide_May_2020.pdf 